\title{
Boronic Acid Catalyzed Dehydrative Peptide Synthesis
}

\section{Key words}

diboronic acids

amidation

amino acids

peptides<smiles>[R7]C(N)C(=O)OCC(=O)C([R7])NC(=O)OC(C)(C)C</smiles>
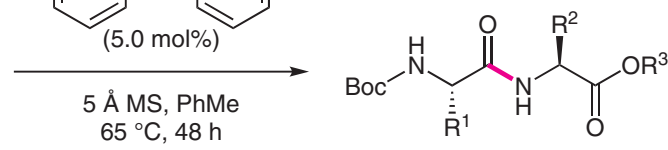

(1.0 equiv)

Selected examples:<smiles>O=C(NC(Cc1ccccc1)C(=O)NC(Cc1ccccc1)C(=O)OCc1ccccc1)c1ccccc1</smiles>

$90 \%$ yield, $d r=98: 2$<smiles>CC(C)(C)OC(=O)N[C@H](CCCC(=O)OCc1ccccc1)C(=O)NC(Cc1ccccc1)C(=O)OCc1ccccc1</smiles>

$89 \%$ yield, $d r=95: 5$<smiles>CCCCOC(=O)C(Cc1ccccc1)NC(=O)C(Cc1ccccc1)NC(=O)c1ccccc1</smiles><smiles>CCOC(=O)C1(NC(=O)[C@@H](Cc2ccccc2)NC(=O)OC(C)(C)C)CC1</smiles><smiles>C#CC[C@H](NC(=O)OC(C)(C)C)C(=O)NC(Cc1ccccc1)C(=O)OCc1ccccc1</smiles>

$95 \%$ yield, $d r=98: 2$<smiles>CCC(=O)OCC[C@H](NC(=O)OCc1ccccc1)C(=O)NC(Cc1ccccc1)C(=O)OCc1ccccc1</smiles>

$79 \%$ yield, $\mathrm{dr}=98: 2\left(80^{\circ} \mathrm{C}\right)$<smiles>CCCC(NC(=O)C(Cc1ccccc1)NC(=O)OCc1ccccc1)C(=O)OCc1ccccc1</smiles>

$97 \%$ yield, $\mathrm{dr}>99: 1\left(80^{\circ} \mathrm{C}\right)$<smiles>CC(C)(C)COC(=O)C(CCCCNC(=O)OC(C)(C)C)NC(=O)[C@@H](Cc1ccccc1)NC(=O)OCc1ccccc1</smiles><smiles>CCCC(NC(=O)OCc1ccccc1)C(=O)NC(Cc1ccccc1)C(=O)OCc1ccccc1</smiles>

$82 \%$ yield, $d r=97: 3$<smiles>O=C(OCc1ccccc1)C(Cc1ccccc1)NC(=O)C1CCCN1C(=O)OCc1ccccc1</smiles>

$73 \%$ yield, $\mathrm{dr}=91: 9\left(80^{\circ} \mathrm{C}, 72 \mathrm{~h}\right)$<smiles>CC(C)(C)OC(=O)CC(NC(=O)C(Cc1ccccc1)NC(=O)OCc1ccccc1)C(C)(C)C</smiles>

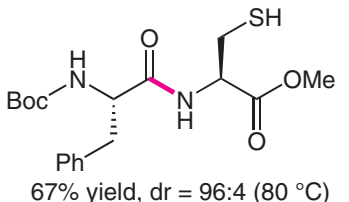

Significance: The amide group is an essential functional groups that exists ubiquitously in natural products, pharmaceuticals, and the like. The authors describe a boronic acid catalyzed dehydrative amidation of amino acids.
Comment: This amide bond formation from amino acids catalyzed by a gem-diboronic acid proceeds smoothly to give the desired peptides in moderate to high yields without significant loss of stereochemical integrity. 